\title{
Occupational Stress among Teachers in Private Senior Secondary Schools in Botswana: Causes and
}

\section{Consequences}

\author{
Som Pal Baliyan ${ }^{1, *}$, Pritika Singh Baliyan ${ }^{2} \&$ Sello Mokoena ${ }^{3}$ \\ ${ }^{1}$ Department of Educational Foundations, Faculty of Education, University of Botswana, \\ Gaborone, Botswana \\ ${ }^{2}$ Department of Accounting and Finance, Faculty of Business, University of Botswana, \\ Gaborone, Botswana \\ ${ }^{3}$ Department of Education Leadership and Management, College of Education, University of \\ South Africa, Pretoria, South Africa \\ *Corresponding author: Department of Educational Foundations, Faculty of Education, \\ University of Botswana, Gaborone, Botswana.E-mail: baliyansom@gmail.com
}

Received: May 2, 2018 Accepted: May 30, 2018 Published: June 9, 2018

doi:10.5296/ije.v10i2.13085 URL: https://doi.org/10.5296/ije.v10i2.13085

\begin{abstract}
Observing the importance of stress among employees, this study was conducted to investigate the causes and effects of stress among private secondary school teachers in Botswana. The specific objectives were to identify the causes of work related stress, to find out the effect of work related stress on performance, to explore and suggest ways of preventing work related stress among teachers. The findings of the study should guide the stakeholders especially policy makers towards reducing the stress in teachers. The study was conducted in two phases; pilot phase and final phase. In pilot phase, sampled teachers were interviewed to collect basic information on teachers stress helped in construction of data collection instrument. In the final phase, data was collected through a survey of 90 stratified random sampled teachers using a validated and reliable questionnaire. The data analysis was done through the descriptive statistics whereby mean and standard deviations were calculated. The school policies contradicting with working environment, too much work load (teaching and extra duties) and pupils indiscipline in class were identified the three most important causes of stress among teachers whereas; low morale and motivation, increase in job dissatisfaction and conflict at work place were the three important effects of stress. Effective planning and implementation, prioritizing work and ignoring the stressor environment were identified the three major ways to reduce stress. It was recommended that possible attempts should be made to reduce workload of teachers. Strategies should be devised and implemented to reduce
\end{abstract}


indiscipline among students. Teachers should focus on proper planning and implantation of their work based on priority.

Keywords: occupational stress, teacher stress, causes of stress, ways to reduce stress, private secondary schools

\section{Introduction}

Everyone has experienced stress in the life. Stress is common to the human condition in life. It is also a significant problem because the same life events which make one person disturbed can be an invigorating experience for another (Selye, 1956). Stress which is a general term used for pressure that people are exposed to in life may be defined as the individual harmony effort that the person displays against a stimulant which has excessive psychological and physical pressure on the person when a person feels insufficient in dealing with demands and challenges in life, he/she experiences stress (Griffins, 1990). Stress is a situation in which a person is required to perform the tasks that threaten to exceed the person's ability and resources for meeting it, under conditions where he or she expects a large difference in the rewards from meeting the demands or not. According to Moorhead and Graffin (2004) stress is a person's adaptive response to a stimulus that places excessive psychological or physical demand on him or her. Stress at work resulting from increasing complexities of work and its divergent demand has become a prominent and pervading feature of the modern organizations. Stress is a pressure of adverse influences, circumstances (such as stress of teaching) that disturbs the natural physiological balance of the body (Robinson, 2007). Pendharkar \& Vaishnav (2016) are of the view that stress is the individual's response to the events which are stressors. Occupational stress may be the result of the individual characteristics of the person or related to his/her environment (Bachkirova, 2005; Tytherileigh, Betoret, 2006; Grebennikov and Wiggins, 2006; Jepson and Forrest, 2006; Lazuras, 2006 and Zhang, 2007). Life events and the stress they place on the individual are not the problem until the individual fails to handle the situation competently and engages in poor coping skills.

Occupational stress has significant effects on psychology of a human and leaves a serious account of the health and behavioral consequences (Fletcher, 1991). Stress needs to be understood within the particular occupational context in which it occurs. Social change and economic imperatives have challenged the teaching profession over the period of time, making it important to document the effects of these challenges and changes on teachers. Research has supported the view that teaching is a stressful occupation (Dworkin, Haney, Dworkin \& Telschow, 1990; Kyriacou, 1987; Schwab, Jackson, \& Schuler, 1986; Dewe, P.J. (1986).) and this stress has increased as the relationship between society and education has become more complex (Esteve \& Fracchia, 1986). The definition of teacher stress given by Kyriacou (2001) stating that teachers stress may be defined as the experience by teacher of unpleasant, negative emotion such as anger, anxiety, frustration or depression resulting from some aspect of their work as a teacher. Teacher can also involve a negative emotional experience associated with the level of pressure and demands made on an individual, as well 
as the degree of mismatch between these demands and his or her ability to cope with those demands. In particularly teachers stress means a situation where the teachers are exposed to certain unwanted environmental factors which exist within the school (internal factors) or outside the school (external factors). Sources of stress may be classified as individual, organization, and outside organization (Gupta, 1991).

Teachers are the most valuable assets of any country as they impart knowledge and skills to students who after completing school join different sectors of the country, starting to contribute towards the economy and development of their country. Stress is often accepted as an inescapable aspect of teaching. Teachers face numerous organizational stressors that affect teachers differently across different contexts; student misbehavior (Kokkinos, 2007), workload and student behaviour (Klassesn, 2010), role conflict, school stress, role overload, task stress, management style, role ambiguity, supervisory support and peer support (Adams, 2001), pupil behaviour (Robertson \& Dunsumir, 2012) and, teachers coping abilities ( Richards, 2012). Teachers describe how their personal and professional lives are affected by work-related stress-it seems that all suffer to some extent, and in the worst cases teachers fear they will be forced to leave the profession to escape the impact of teaching stress on their lives. Kyriacou (1987) indicated that research has found that the sources of teacher stress are not clear cut and those differences due to characteristics such as sex, age, teaching experience, and post held are prone to cause inconsistent findings. Additional context-specific studies are required to clarify the complex nature of the factors producing stress amongst teachers. Although a certain amount of stress might be seen as a good thing and helps to promote a high level of performance, too much stress can have a negative impact on employees and employers alike.

Although the teaching profession has traditionally been regarded as low stress occupation but during the past two decades the situation is somersaulted. Occupational stress has become increasingly common in teaching profession largely because of increased occupational complexities and increased economic pressure on individuals. The stress affects the performance of a teacher. The performance of a teacher refers to the behavior of the teacher which changes in surrounding, environment in such way that when a particular task is assigned to a teacher he/she takes successfully. The teachers always complain about work overload, role ambiguity, unrealistic job challenges and ineffective communication. This often negatively influence work performance for individual teachers and the schools. The teachers are responsible for a number of extra works besides teaching. A good teacher has not only to teach in the way that he/ she also has to manage time and duties assigned to him apart from teaching, like managing school ethics and discipline in class, motivating learners/pupils ensuring their interaction and maintaining proper link with the community.

Teaching is becoming more challenging as a profession in general and in private schools in particular. Private schools expect a lot from the teachers so as such schools can survive in the current competitive environment of private education. Teachers working in different schools especially private schools are always under great pressure to meet expectations of their customers. In this process of meeting expectations of their customers, teachers in the schools especially in private schools, are exposed to certain unwanted internal and external 
environmental factors which disturb teachers' abilities and results in development of feeling tiredness and strain. Private schools teachers in Botswana face a variety of challenges namely; an acute shortage of resources likes laboratories, furniture and sport facilities, computer labs and other instructional resources. The scarcity of these resources confronts teachers with tremendous problems. Overwhelming parents are illiterate and hence unable to prepare their children for learning; they only depend on teachers for their children's education. In addition to these challenges, private schools have strict rules and regulation for teachers to adhere to. For example, teachers are expected to prepare lesson plans, punctuality and regularity in their duty. In many schools students come from different regions representing different cultures and languages. Mostly, the classes are overcrowded facing teachers with different challenges of discipline and classroom management. In addition, some students come from the Setswana medium schools and find it very difficult to adjust in English-medium classes; hence, pose a serious challenge to teachers.

The increasing demands of the private school managements and growing expectations of the community, with negligible or no support at all pose serious challenges to teachers (Shafa, 2011). Often, these demands are such that the teachers have to ignore their personal life as they have no time apart from work. Teachers in private schools are sacrificing their physical and mental health and social relationships to fulfill their responsibilities at work place. Hassan (2014) and Jani (2017) reported that the private primary school teachers have also found to be highly stressed in comparison to their government primary school teacher counterparts. "The myth about the cushy life of a private school teacher was today exploded as a survey revealed that $85 \%$ of them said excessive workloads were affecting their home life" (Polly Curtis, 2004. p.6). This creates a severe imbalance in most teachers' life to the extent that some opt for an early retirement and some eventually leave the job. It is these and many other expectations and demands that make the job of a teacher difficult to manage and stressful.

In order to get the work done effectively, the organization or manager should properly manage the level of stress. To achieve this organizational objective, all the factors which influence stress should be properly identified and measured (Kamalakumati and Ambika, 2013). Work related stress affects negatively the performance of teachers in private schools, as it disrupt an individual's emotional stability, physical and psychological disposition. In long run, stress can be a threat to a schools performance and the school may struggle for its survival. Therefore, it is important to examine the causes of stress and its effects on the performance of teachers. A number of studies have been conducted on the teachers stress in the world. In Botswana, there is a very limited research have been done in this area. No study has been conducted on the causes of stress and its influence on the teacher's performance in private senior secondary schools in Botswana. Therefore, this study was to investigate the cause of stress and its effects on the performance of teachers. The main objectives of this research are i) To identify the factors contributing to stress among teachers, ii) To determine the effects of stress on teachers performance and, iii) To explore and suggest the ways to reduce stress among teachers in order to enhance the teachers performance. The intention of this study is to examine the cause and influences of work-related stress and other elements of 
the work situation. Therefore, the definition of stress used here is confined to the teacher work-related stress excluding the stress arising from a teacher's non-work situation.

\section{Review of Literature}

\subsection{Causes of Stress}

The researchers cannot understand teacher's stress without identifying the major causes of stress. Common stressors are work overload, time restraints, in disciplined student behaviour, working conditions, relationships with colleagues, lack of resources and the physical demands of teaching have been identified repeatedly by researchers (Albertson \& Kagan, 1987; Cooper \& Kelly, 1993; Dewe, 1986; Finlay-Jones, 1986; Fletcher \& Payne, 1982; Hargreaves, 1990; Kyriacou \& Suttcliffe,1979; O'Connor \& Clarke, 1990; Otto, 1986; Trendall, 1989; Borg, Riding and Falzon (1991). Skaalvik and Skaalvik (2015) found seven categories of stressors that was identified by more than half of the teachers: disruptive student behavior, workload and time pressure, student diversity and working to adapt teaching to students' needs, lack of autonomy, lack of shared goals and values, problems and conflicts related to teamwork, and lack of status. They reported that teachers at different ages experienced the same stressors at school, but that senior teachers needed increasingly more time to recover from stress.

Armstrong (1992) said that stress is a feature of organizational life associated with getting work done, relating to other people and being subjected to change, supervision and the exercise of power. He listed the following as causes of work related stress nature of work itself, role in the organization, poor relationships within the organization, feelings about job or career (lack of job security, over promotion or under promotion) and support at work. Schembari (1994) indicated that teachers' workload had increased over years and that teachers work longest hours up to 47 hours per week. He discussed teaching as a 'multi-track activity' in which teachers are required to do several things at once, in responding to the needs of students or their interactions with colleagues. Such multi-track activities also lead to role conflict where teachers felt torn and pulled by the need to fill the different roles; which causes a lot of stress in teachers.

Cooper \& Rothmann (2013) outlined the causes of stress which included administrative policies \& strategies (downsizing and competitive pressure, merit pay plans and advanced technology, rotating work shifts and bureaucratic rules); organizational structure \& design (centralization and formalization, line-staff conflicts, specialization and no opportunity for advancement, role ambiguity and conflict, restrictive, untrusting culture); organizational processes (tight controls and punitive appraisal systems, only downward communication and centralized decision making, little performance feedback, lack of participation in decision making); working conditions (crowded work area, noise, heat or cold and polluted air, physical or mental strain, toxic chemical or radiation).

Sultana et al. (2012) explored the nature and impact of teacher stress in the private schools in Pakistan. Analysis of the stress factors showed that they were inextricably connected with the 
professional, personal and financial dimensions of teacher life. Also, it is noteworthy that the numerous factors were interconnected; i.e. a stress factor falling in a certain dimension (e.g. professional) has implications for the factors falling in the other two dimensions (e.g. personal and financial), and vice versa. The data categorically delineated that the stress factors left various marks on teachers, influencing (often negatively) their morale and motivation and, therefore, impacted their sense of professionalism and classroom performance.

Barling and Kelloway (2006) stated that stress at work is relatively a new phenomenon of modern lifestyle. The nature of work has gone through drastic changes over the last century and it is still changing at whirlwind speed. Professional stress or job related stress poses a threat to physical health. Work related stress in the life of organized worker consequently affects the health of organizations. He found that job stress may be caused by a complex set of reasons including job insecurity, high demand for performance, technology, workplace culture and personal or family problems.

The language difficulties, ethnic intolerance, negative relations between pupils and their teachers are cause of poor result and school drop outs (Polelo, 2003). This negativity or 'sour relations' has result in teachers having wrong perception about the children which can finally be a reason of stress in teachers. Armstrong (2006) suggested that stress at work is caused by role conflict, role ambiguity, unrealistic job challenges and, ineffective communication. There is no doubt that students have many needs and when they are not met or not provided for it can lead to restlessness and frustration of pupils and eventually indiscipline in school causing stress in the school environment. A lackadaisical attitude of school's administration towards the pupils/students welfare is a factor that prompts indiscipline in school. According to Afolabi (1998) discipline is the readiness and willingness of an individual to demonstrate decent and decorous conduct, respect for authority, high sense of responsibility, love for orderliness, eagerness to discharge duties with promptitude and efficiency. When an individual fails to discharge these characteristics, indiscipline is said to have occurred. Indiscipline in schools include the behaviors such as disobedience to teachers and school rules and regulations, stealing of other pupils' properties, Wearing unauthorized assorted dresses, smoking, alcohol and drug consumption, involvement in secret cult activities, immoral relationships with female pupil/student. As learning ability is and performance in every human being is just because of intelligent quotient (IQ) a different environment and or a different notion, the multicultural population of the classroom may be an obstacle for the teacher in reaching the students, which eventually results in ineffective learning as well as teaching and causes stress for the teacher (Fisher, 2010). A heterogeneous class would include students who vary in background, interest, age, gender, personality, motivation, cognitive ability and learning styles. It is so colligated to deliver and to control that mixed ability class which turn into stress for a teacher.

Relationship with management has a positive or negative effect on the staff and obviously on the stress. Poor relations with management may lead to a chronic problem which may cause anxiety and depression. Many teachers who do not share good relationship with the management often report frustration, despair, and confusion and fear (Carron, and Chan 
1996). It is found that relationship with management not only leads to reduction in quality of work but also lead to emotional problems in staff which can lead to under participation in work related activities. The problem of relationship with management has also lead to further problems like unrealistic goals, unsympathetic treatment, time pressured work and lack of control over content and origin of work. According to analytic report on education poor resource management seriously demotivate teachers in most of African countries. It is also reported that he management sometimes becomes biased and tend to put more pressure on certain teachers. These teachers feel they are harshly supervised. Sometimes such teachers have few say in decision making. Such behavior may lead to teacher feeling that supervision is harsh and may lead to stress (Eva and Stopi, 2002). Management tends to be authoritarian with limited participation, delegation and communication with respect to major school management functions. Teachers subjected to this type of supervision may feel as they are treated as children.

\subsection{Effects of Work Related Stress}

The teaching profession is one of the most stressful professions; it includes interaction with students, parents, colleagues and the school management (Kyriacon, 1997). Besides interaction, his role of the teacher has also influenced teachers' stress. Effects of stress can be categorized as physiological, psychological and behavioral effects. (Cooper and Dewey, 2004) state some examples of physiological effects are; headache, being tired, digestion and ulcer problem, physical exhaustion, increased heart rate and being out of breath. Psychological or emotional effects can be anxiety, depression, anger, frustration, dissatisfaction, being lonely, and reduction in moral and general wellbeing, poor decision making and bad judgment. Behavioural effects include over/under eating, frequent smoking, taking sedatives, sleeping problems. (Bradley, 2004; Conley and Woosly, 2004; Cox et al, 2000; Dollard et al, 2003; Black (2003) mentioned physical and emotional exhaustion as one of the most important stress outcome of teacher' stress.

Ralph (1998) reported that stress can adversely affect teachers' work performance. It may cause job dissatisfaction, low productivity level, concentration problems, having problems in managing time and meeting deadlines and feeling of inadequacy. The relationship with colleagues is also negatively affected by stress, such as not willing to cooperate, low level of motivation, role conflict, reluctant to have supportive relationship, having aggressive and irritable feelings, becoming more introverted, inability to communicate with colleagues and having conflicts. Teachers also have behavioral problems resulting from stress such as poor appetite, increased alcohol, cigarettes, coffee consumption, having nightmares, inability to feel relaxed and being too fussy. William and Cooper (2002) indicated that the costs of stress include sickness absence, staff turnover and accidents. The invisible costs of work related stress especially long term stress are poor service, difficult working relationships, low morale, and poor quality, lack of innovation, poor decision making and low productivity. Therefore, these effects of work related stress cost the organization a lot and can negatively influence its survival. Stress can be a result of role conflict which arises from inadequate or inappropriate role definition. Role conflict may cause people to behave in manner inconsistent with their expected behavior patterns. While a certain degree of stress can be healthy (refers to as 
eustress) in maintaining a good level of performance, too much stress (referred to as distress) can be harmful. Distress can lead to tension, frustration, dissatisfaction, de-motivation and poor performance and, difficulties in both communication and interpersonal relationship.

In addition to above mentioned effects of stress on teachers' performance, there are also some organizational effects of stress such as low level of performance and productivity, too much expenses for health problems, high turnover, absenteeism, failures and accidents at work, feeling of alienation to work. (Balta and Baltas, 2002). Teachers' stress is considered rising and has become a challenge for the employer and because of high level of stress, results in low productivity, leaving the jobs, increased absenteeism and collection of other employee problems like alcoholism and drug abuse; and most of cardio vascular problems(Menez, 2005). Skaalvik and Skaalvik (2015) reported that both the workload and the accumulation of numerous sources of stress have a number of maladaptive consequences. Important consequences for a number of the teachers were physical and emotional exhaustion, the sacrifice of social lives, increasing instances of sick leave, the reduction of teachers' employment with economic consequences for the individual teachers, and early retirement, with disability pension for some teachers.

Armstrong (1992) has illustrated that stress is always with us, it manifests itself at different stages and levels as we move through life. Though many of life's problems are minor, stress can be fatal. For this reason stress must be identified and methodically reduced. Stress can result in increased blood pressure, heart rate and respiration, headaches, ulcers, stomach problems, nervous stomach, general anxiety, emotional response (anger, fear, quiet, lack of love), muscle constriction commonly in the neck or back. It can also boost to low morale, health and job complaints and employee turnover often provides the first signs of job stress. Stressed individuals tend to become susceptible to a variety of physical and mental problems. Ulcers, headaches, depression, anxiety and respiratory and circulatory problems have been linked to stress. Excessive stress can lead to total breakdown in mental and physical health, exhaustion and unhealthy forms of escapism such as alcohol or drug abuse. All these effects of stress can cost to an organization in the form of increased dissatisfaction or lack of commitment, poor overall performance, low staff turnover, lost time and lost productivity.

\subsection{Stress and Productivity}

Several researches have been conducted on stress and its influence on the productivity. Hira and Anam (2012) investigated the impact of job stress on the counter-productive work behaviour (CWB) using a cross sectional analysis. They linked job stress with increased absenteeism, low productivity, low motivation, financial loss and counter-productive work behaviour. Their results further revealed that high degree of attention demanded by their work which is beyond job range, excessive workload than normal work, poor communication, no appreciation received from management, unfair performance evaluation system, inappropriate working conditions such as low salaries and rewards are common factors heightening stress and counter-productive work behaviour. Syed, et.al. (2013) investigated the relationship between job stress and productivity in public health sector. Results revealed that, lack of financial awards, inflexibility in work hours, personal issues and bureaucratic 
management system are negatively correlated with employee productivity while, lack of financial rewards contributed more in creating job stress among the public health sector employees.

Halkos \& Dimitrios, (2008) used factor analysis to identify the responsible factors for correlation among a large number of quantitative and qualitative variables and their influence on productivity. However, the extracted factors showed that productivity is an element affected by two qualitative factors - stress and satisfaction. Menyezwa (2006) worked on the impact of stress on productivity of employees at the education training and development practices sector in Pretoria, South Africa. The findings suggested that the stress affected productivity negatively. Lack of care from employers was also found to be a reflection of huge dissatisfaction that undoubtedly lowered productivity. Ayodele (2014) and Indhu \& Thirumakkal (2015) found that stress affects employee productivity negatively.

\subsection{Ways to Reduce Stress}

Stressors are always present in the profession of teaching, which suggests teachers should learn techniques to manage in order to remain an effective teacher. It is better for teachers to be proactive rather than reactive with management of stress (Nigel et. al., 2003).He established that clear classroom expectations can alleviate many of the stressors existing in a classroom between the teacher and the student. A good practice is for the teacher to set up those expectations from the formation of class to prevent any escalation of anxiety in the classroom. Osher et al 2007 stipulated some of the ways for establishing clear classroom expectation, method of instruction, method of assessment, code of conduct, parental involvement and social support. Change in lifestyle and other small strategies can help to deal with stress the work can be delegated or shared and avoid confrontation with problematic colleagues. Learning to be assertive taking regular exercises and avoiding alcohol and drugs can reduce stress. (Joseph 2003) on the other hand eating a healthy balanced diet rich in fruits and vegetables, finding humour in stressful situation, time management, talking to friends/family, sharing thoughts and fear can fight stress. The person who is stressed should never take more work. Listening to music or relaxation are some of the simple ways to reduce stress.

\section{Methodology}

This quantitative and descriptive study was undertaken in private senior secondary schools in Botswana. Therefore, the teachers in private senior secondary schools in Botswana were the population of the study. A stratified random sampling method was adopted for sampling of schools and teachers. The strata were the location of schools; rural and urban and the second strata was gender of teachers; male and female teachers. The stratified sampling was deemed appropriate to avoid order to avoid gender as well as location specific discrimination which might have effect on the results of the study. For the purpose of the study, a total of six schools; three from rural and three from urban were purposively selected. Thereafter, a total of 90 teachers including 30 from each school were randomly sampled from the six selected 
schools. A sampling plan is presented in Table 1.

The study was completed in two phases; pilot phase and final phase. In the pilot phase of the study, ten teachers were purposively selected and interviewed in order to prepare a list of the possible causes, effects and the ways to reduce stress. The purpose of the pilot phase was to collect information to form the base of final phase of the study.

Table 1. Sampling of the Study

\begin{tabular}{|c|c|c|c|}
\hline Gender $\quad$ Location of School & $\begin{array}{l}\text { Male } \\
\text { Teachers }\end{array}$ & $\begin{array}{l}\text { Female } \\
\text { Teachers }\end{array}$ & $\begin{array}{l}\text { Total } \\
\text { Teachers }\end{array}$ \\
\hline Rural schools & 25 & 20 & 45 \\
\hline Urban schools & 20 & 25 & 45 \\
\hline Total Teachers & 45 & 45 & 90 \\
\hline
\end{tabular}

In the final phase of the study, a survey was conducted using a validated and reliable questionnaire to collect the data for the study. A questionnaire for final survey was prepared based on the responses of the interviews of ten teachers during pilot study. However, the 10 teachers selected for pilot survey were not part of the final survey. The questionnaire was given to three education experts for validation of the contents. After validation of the questionnaire, it was pilot tested with 10 teachers for its reliability. The reliability coefficient for the causes of stress, effect of stress and ways to reduces stress was calculated and recorded $.88, .82$ and .91 , respectively. The final survey questionnaire included 10 causes, 10 effects and 10 ways to reduce the stress. A four point Likerts scale was adopted to get the responses from the sampled respondents. The sampled teachers were asked to respond on a four-point Likert scale (Strongly Disagree $=1$, Disagree $=2$, Agree $=3$ and Strongly Agree $=$ 4). Data collected were analyzed using descriptive statistical methods of mean and standard deviation.

\section{Results and Discussion}

The findings of the study are presented according to objectives of the study as follows.

\subsection{Causes of Stress in Teachers}

Ten causes of stress were identified and the mean scores of each cause are presented in Table 2. A total of ten causes of stress were responded in the survey questionnaire (Table 2). The sampled teachers as respondents rated these causes on a four-point Liker scale (Strongly Disagree $=1$, Disagree $=2$, Agree $=3$ and Strongly Agree $=4)$. The mean scores for causes of stress indicated that school policies contradicting with working environment $(\mathrm{M}=3.11)$ and too much work load - teaching and extra duties $(\mathrm{M}=3.07)$ followed by pupilsindiscipline in class $(\mathrm{M}=2.96)$ were the top three important causes of stress in the teachers. However, poor lesson planning and teaching $(\mathrm{M}=1.21)$ and personal problems $(\mathrm{M}=3.11)$ were the 
least important causes of the stress.

Table 2. Mean Scores for Causes of Stress in Teachers in Private Secondary Schools

\begin{tabular}{lll}
\hline Causes of stress & M & SD \\
\hline 1. School policies contradicting with working environment & 3.11 & .891 \\
2. Too much work load (Teaching and extra duties) & 3.07 & .742 \\
3. Pupils indiscipline in class & 2.96 & .652 \\
4. Lack of time for family and other social commitments & 2.79 & .922 \\
5. Accountability for student's performance & 2.32 & .946 \\
6. Difficult to teach mixed ability students & 2.12 & 1.21 \\
7. Poor Relationship with supervisors & 1.74 & 1.04 \\
8. Poor parental involvement & 1.37 & .566 \\
9. Poor lesson planning and teaching & 1.21 & .641 \\
10. Personal problems & 1.13 & 1.56 \\
\hline
\end{tabular}

Administrative policies was the top ranked cause of the stress among the teachers and this finding is supported by Cooper \& Rothmann (2013) who reported that administrative policies an strategies was among the top causes of stress among teaches. The school policies as a cause of stress was supported by Luthans, (2005) who outlined the causes of stress which included administrative policies \& strategies, organizational structure \& design and, organizational processes. The finding of too much work load teaching and extra duties as a cause of stress in teachers resembles with the findings of Schembari (1994) who indicated that teachers' workload had increased over years and that teachers work longest hours. Further, Skaalvik \& Skaalvik (2016) found that workload strongly predicted the stress among teachers. Teaching is as a multi-task activity in which teachers are required to do several things at once. Such multi-track activities lead to role conflict where teachers felt torn and pulled by the need to fill the different roles which causes a lot of stress in teachers.

The indiscipline in class as the important cause of stress among teachers was supported by the findings of Lewis (1999) and, Skaalvik and Skaalvik (2015) who reported that disruptive students' behaviors and classroom discipline are the major cause of teachers' stress as teachers are unable to discipline pupils. They would prepare overall maintaining discipline emerged as a stressor, with those worst affected being teachers who placed particular emphasis on pupil empowerment. It can be concluded that there should be a deep review of the school policies and working environment. Attempts should also be made to reduce the workload of teachers. The strategies should be formulated and implemented so as to curb the indiscipline of students in the class.

\subsection{Effects of Stress on Performance of Teachers}

There were ten effects of stress identified and the mean scores of each effect are presented in table 3. 


\section{Mll Macrothink}

Table 3. Mean Scores for Effects of Stress on Performance of Teachers in Senior Secondary Schools

\begin{tabular}{lll}
\hline Effects of stress & M & SD \\
\hline 1. Low morale and motivation & 3.56 & .477 \\
2. Increase in job dissatisfaction & 3.24 & .948 \\
3. Conflict at work place & 3.12 & .769 \\
4. Difficult to manage and meet deadlines & 3.04 & .716 \\
5. Decrease in concentration & 2.78 & .988 \\
6. Decrease in overall performance at work & 2.61 & 1.12 \\
7. Increase chronic diseases & 2.22 & .863 \\
8. Increase in alcohol and drug abuse & 1.92 & 1.49 \\
9. Early retirement/quitting the job & 1.37 & 1.67 \\
10. Absenteeism from work & 1.11 & 1.59 \\
\hline
\end{tabular}

Table 3 indicated that low morale and motivation $(\mathrm{M}=3.56)$ and increase in job dissatisfaction $(\mathrm{M}=3.24)$ followed by conflict ate work place $(\mathrm{M}=3.12)$ were the top three major effects of stress in the teachers. However, early retirement/quitting the job $(\mathrm{M}=1.37)$ and absenteeism from work $(\mathrm{M}=1.11)$ were the least important causes of the stress. It can be concluded that the stress should be minimized to improve the morale and motivate the teachers which influence their performance. The boost in morale can also minimize job dissatisfaction as well as early retirement/quitting the job as well as absenteeism from work. Stress can be a factor that makes teachers leave the profession or retire early (Skaalvik \& Skaalvik, 2011; Van Droogenbroeck \& Spruyt, 2014). To reduce the cases of early retirement, government should device effective strategies to mitigate the effect of stress among private senior secondary school teachers.

\subsection{Ways to Reduce Stress in Teachers}

The respondents identified eleven ways which can reduce stress in teachers. The mean scores of each ways are presented in Table 4 .

Table 4. Mean Scores for Ways to Reduce Stressing Teachers at Private Secondary Schools

\begin{tabular}{llc}
\hline Ways of reducing stress & M & SD \\
\hline 1. Effective planning and implementation & 3.24 & .963 \\
(Effective time management) & & \\
2. Prioritizing work & 3.13 & .777 \\
3. Ignoring the stressful environment as possible & 3.05 & 1.89 \\
4. be busy always & 2.92 & .865 \\
5. Use relaxation techniques & 2.78 & 1.02 \\
6. Being proactive & 2.57 & .564 \\
7. Improve on students' discipline & 2.32 & .919 \\
8. Solve personal problems in time & 2.19 & 1.07 \\
9. Delegating work if possible & 1.80 & 1.59 \\
10. Seeking professional counseling & 1.27 & .899 \\
11. Having a good network of people & 1.09 & 1.73 \\
\hline
\end{tabular}


Table 4 highlights that among the eleven identified ways to reduce stress, effective planning and implementation $(\mathrm{M}=3.24)$ and prioritizing work $(\mathrm{M}=3.13)$ followed by ignoring the stressor environment $(\mathrm{M}=3.05)$ were the top three important ways to reduce stressing the teachers. However, seeking professional counseling $(\mathrm{M}=1.27)$ and having a good network of people $(\mathrm{M}=1.09)$ were the least important ways to reduce the stress in teachers at private senior secondary school.

\section{Conclusion and Recommendations}

The study identified the causes of work related stress, the effects of work related stress on performance, suggested ways of preventing work related stress among private secondary school teachers. Based on the findings, it was concluded that the school policies contradicting with working environment, too much work load (teaching and extra duties) followed by pupils' indiscipline in class were the top three important causes of stress. Therefore, it can be recommended that the school policies and working environment need to be analyzed in relation to the stress factor for teachers. Attempts should be made to reduce the workload of teachers. Also, strategies should be devised and implemented to reduce indiscipline among students.

Low morale and motivation increase in job dissatisfaction and conflict at work place were the top three major effects of stress on the performance of the teachers. It was therefore suggested that effective strategies for improving the morale, increase in job satisfaction should be implemented in the private secondary schools.

Effective planning and implementation, prioritizing work and ignoring the stressor environment were explored as the top three most effective ways to reduce stress. It was recommended that teachers should focus on proper planning and implantation of their work at priority basis. Also, teacher should try to abstain from any potential environment causing stress.

\section{References}

Adams, E. (2001). A proposed causal model of vocational teacher stress. Journal of Vocational Education \& Training, 53, 223-246.https://doi.org/10.1080/13636820100200153

Aftab, H., \& Javeed, A. (2012). The impact of job stress on the counter-productive work behavior (CWB): a case study from the financial sector of Pakistan. Interdisciplinary journal of contemporary research in business, 4(7), 590-604.

Albertson, L.M., \& Kalgan, D.M. (1987). Occupational stress among teachers. Journal of Research and Development in Education, 21, 69-77.

Alluisi, E. A. (1982). Stress and stressors, commonplace and otherwise. Human performance and productivity: Stress and performance effectiveness, 3, 1-10. 
Armstrong, M. (2006). A handbook of human resource management practice. Kogan Page Publishers.

Ayodele, E. J. (2014). Occupational Stress and Employee Productivity in Work Place. International Journal of Scientific Research in Education, 7(2), 157-165.

Bachkirova, T. (2006). Teacher stress and personal values: An exploratory study. School psychology international, 26(3), 340-352.https://doi.org/10.1177/0143034305055978

Balt, A., \& Baltas, Z. (2002). Stress in ways of coping with stress (21stEd.). Istanbul: Remzi Bookstore.

Betoret, F.D. (2006). Stressors, self-efficacy, coping resources and burnout among secondary school teachers in Spain. Educational Psychology, 26(4), 519-539. https://doi.org/10.1080/01443410500342492

Black, S. (2003). Stressed Out in the Classroom. American school board journal, 190(10), 36-38.

Borg, M. G., Riding, R. J., \& Falzon, J. M. (1991). Stress in teaching: A study of occupational stress and its determinants, job satisfaction and career commitment among $\begin{array}{llll}\text { primary schoolteachers. Educational Psychology, 11(1), 59-75. } & \text {. }\end{array}$ https://doi.org/10.1080/0144341910110104

Bradley, G. (2004). Job strain and healthy work in teachers: A test of the demands-controlsupport model (Doctoral dissertation, Griffith University).

Conley, S., \& Woosley, S. A. (2000). Teacher role stress, higher order needs and work outcomes. Journal of Educational Administration, 38(2), 179-201. https://doi.org/10.1108/09578230010320163

Cooper, C. L., \& Kelly, M. (1993). Occupational stress in head teachers: a national UK study. British journal of educational psychology, 63(1), 130-143. https://doi.org/10.1111/j.2044-8279.1993.tb01046.x

Cooper, C., \& Rothmann, I. (2013). Organizational and work psychology: Topics in applied psychology.

Cooper, C., \& Travers, C. (2012). Teachers under pressure: Stress in the teaching profession. Routledge.

Cox, T., Griffiths, A., \& Rial-González, E. (2000). Research on work-related stress. European Communities.

Dewe, P.J. (1986). An investigation into the causes and consequences of teacher stress. New Zealand Journal of Educational Studies, 21, 145-157.

Dollard, M., Winefield, H. R., \& Winefield, A. H. (Eds.). (2003). Occupational stress in the service professions. CRC Press. https://doi.org/10.4324/9780203422809

Dworkin, A. G., Haney, C. A., Dworkin, R. J., \& Telschow, R. L. (1990). Stress and illness 
behavior among urban public school teachers. Educational Administration Quarterly, 26(1), 60-72. https://doi.org/10.1177/0013161X90026001004

Esteve, J. M., \& Fracchia, A. F. B. (1986). Inoculation against stress: A technique for beginning teachers. European Journal of Teacher Education, 9(3), 261-269. https://doi.org/10.1080/0261976860090307

Fimian, M. J. (1987). Teacher stress: An expert appraisal. Psychology in the Schools, 24(1), 5-14.

https://doi.org/10.1002/1520-6807(198701)24:1\%3C5::AID-PITS2310240102\%3E3.0.C $\mathrm{O} ; 2-\mathrm{R}$

Finlay-Jones, R. (1986). Factors in the teaching environment associated with severe psychological distress among school teachers. Australian \& New Zealand Journal of Psychiatry, 20(3), 304-313. https://doi.org/10.3109/00048678609158878

Fletcher, B. C., \& Payne, R. L. (1982). Levels of reported stressors and strains amongst schoolteachers: Some UK data. Educational Review, 34(3), 267-278. https://doi.org/10.1080/0013191820340308

Fletcher, B.C. (1991). Work, Stress, Disease and Life Expectancy. New York: John Wiley and Sons.

Grebennikov, L., \& Wiggins, M. (2006). Psychological effects of classroom noise on early childhood teachers. The Australian educational researcher, 33(3), 35-53. https://doi.org/10.1007/BF03216841

Halkos, G. E., \& Dimitrios, B. (2008). The influence of stress and satisfaction on productivity. MPRA Paper No. 39654, 1-26.

Hargreaves, A. (1990). Teachers' work and the politics of time and space. International Journal of Qualitative Studies in Education, 3(4), 303-320. https://doi.org/10.1080/0951839900030401

Hasan, A. (2014). A study of occupational stress of primary school teachers. Educationia confab, 3(4), 11-19.

Hira, A. \& Anam, J. (2012). The Impact of Job Stress on the Counter-productive Work Behavior (CWB) A Case Study from the financial Sector of Pakistan. Interdisciplinary Journal of Contemporary Research in Business, 4(7), 590-604.

Hogan, R., \& Hogan, J. C. (1982). Subjective correlates of stress and human performance. Human performance and productivity: Stress and performance effectiveness, 3, 141-163.

Indhu, M. G., \& Thirumakkal, M. (2015). A Study on Role of Occupational Stress on Employees Productivity. International Journal of Management, 6(1), 560-572.

Jani, B. (2017). Stress of teachers working at primary school in kalahandi. International Education and Research Journal, 3(1). 
Jepson, E., \& Forrest, S. (2006). Individual contributory factors in teacher stress: The role of achievement striving and occupational commitment. British Journal of Educational Psychology, 76(1), 183-197. https://doi.org/10.1348/000709905X37299

Joseph, R. (2000). Stress free teaching: a practical guide to tackling stress in teaching, lecturing and tutoring. Routledge.

Kamalakumati, K., \& Ambika, P. (2013). A study on the effect of Stress on performance of employees in Commercial Bank of Ceylon in the Eastern Province. European Journal of Business and Management, 7(27), 87-95.

Klassen, R. M. (2010). Teacher Stress: The Mediating Role of Collective Efficacy Beliefs. The Journal of Educational Research, 103(5), 342-350. https://doi.org/10.1080/00220670903383069

Kokkinos, C. M. (2007). Job stressors, personality and burnout in primary school teachers. British Journal of Educational Psychology, 77, 229-243. https://doi.org/10.1348/000709905X90344

Kyriacou, C. (1987). Teacher stress and burnout: An international review. Educational research, 29(2), 146-152. https://doi.org/10.1080/0013188870290207

Kyriacou, C. (2001). Teacher stress: Directions for future research. Educational review, 53(1), 27-35. https://doi.org/10.1080/0013188790210202

Kyriacou, C., \& Sutcliffe, J. (1979). Teacher stress and satisfaction. Educational Research, 21(2), 89-96. https://doi.org/10.1080/0013188790210202

Lazarus, R. S., Deese, J., \& Osler, S. F. (1952). The effects of psychological stress upon performance. Psychological bulletin, 49(4), 293. https://doi.org/10.1037/h0061145

Lazuras, L. (2006). Occupational stress, negative affectivity and physical health in special and general education teachers in Greece. British Journal of Special Education, 33(4), 204-209. https://doi.org/10.1111/j.1467-8578.2006.00440.x

Lewis, R. (1999). Teachers coping with the stress of classroom discipline. Social Psychology of Education, 3(3), 155-171. https://doi.org/10.1023/A:1009627827937

Meneze, M. M. (2005). The Impact of Stress on productivity at Education Training \& Development Practices: Sector Education and Training Authority. Pretoria, South Africa: University of Pretoria.

Menze, M. N. M. (2006). The impact of stress on productivity of employees at the education training and development practices: sector education and training authority (Doctoral dissertation, University of Pretoria).

O'Connor, P. R., \& Clarke, V. A. (1990). Determinants of teacher stress. Australian Journal of Education, 34(1), 41-51. https://doi.org/10.1177/000494419003400103

Osher, D., Sprague, J., Weissberg, R. P., Axelrod, J., Keenan, S., Kendziora, K., \& Zins, J. E. 
(2008). A comprehensive approach to promoting social, emotional, and academic growth in contemporary schools. Best practices in school psychology, 4, 1263-1278.

Otto, R. (1986). Teachers under Stress: Health Hazards in a Work Role and Modes of Response. Melbourne: Hill of Content.

Pendharkar, P., \& Vaishnav, R. (2016). Occupational Stress And Family Environment (No. 2016-03 08).

Polly Curtis. (Monday 5 April 2004). Private school teachers suffering workload stress. In The Guardian home. Retrieved on March 14, 2012, from http://www.guardian.co.uk/education/2004/apr/05/schools.uk2

Richards, J. (2012). Teacher Stress and Coping Strategies: A National Snapshot. The Educational Forum, 76, 299-316. https://doi.org/10.1080/00131725.2012.682837

Robinson, M. (2007). Chamber's 21st century dictionary. Allied Chambers (India) Limited, New Delhi.

Schuler, R. S. (1980). Definition and conceptualization of stress in organization. Organizational behavior and human performance, 25(2), 184-215. https://doi.org/10.1016/0030-5073(80)90063-X

Schwab, R. L., Jackson, S. E., \& Schuler, R. S. (1986). Educator burnout: Sources and consequences. Educational Research Quarterly, 10(3), 14-30.

Selye, H. (1956). The stress of life. New York, Mc Gran-Hill Book Company.

Shafa, M. D. (2011). Role of head teachers in managing the forces emanating from the external world of schools in Gilgit-Baltistan of Pakistan. American International Journal of Contemporary Research, 1(2), 66.

Skaalvik, E. M., \& Skaalvik, S. (2011). Teacher job satisfaction and motivation to leave the teaching profession: relations with school context, feeling of belonging, and emotional exhaustion. Teaching and Teacher Education, 27(6), $1029 \mathrm{e} 1038$. https://doi.org/10.1016/j.tate.2011.04.001

Skaalvik, E. M., \& Skaalvik, S. (2015). Job Satisfaction, Stress and Coping Strategies in the Teaching Profession-What Do Teachers Say?. International Education Studies, 8(3), 181. https://doi.org/10.5539/ies.v8n3p181

Skaalvik, E. M., \& Skaalvik, S. (2016). Teacher stress and teacher self-efficacy as predictors of engagement, emotional exhaustion, and motivation to leave the teaching profession. Creative Education, 7(13), 1785. https://doi.org/10.4236/ce.2016.713182

Sultana, B., Bano, Y., Bano, F., \& Shafa, M. D. (2012). The nature and impact of teacher stress in the private schools of Gilgit-Baltistan, Pakistan. International Journal of Academic Research in Progressive Education and Development, 1(2), 64-84.

Syed, M., Muhammad A., Aftab Q., \& Shabana N. (2013). Employees' productivity: case of 
azad Kashmir public health sector. Journal of Contemporary Research in Business, 5(3).

Trendall, C. (1989). Stress in teaching and teacher effectiveness: A study of teachers across mainstream and special education. Educational Research, 31(1), 52-58. https://doi.org/10.1080/0013188890310106

Tytherleigh, M. Y., Webb, C., Cooper, C. L., \& Ricketts, C. (2005). Occupational stress in UK higher education institutions: A comparative study of all staff categories. Higher Education Research \& Development, 24(1), 41-61. https://doi.org/10.1080/0729436052000318569

Van Droogenbroeck, F., \& Spruyt, B. (2014). To stop or not to stop: an empirical assessment of the determinants of early retirement among active and retired senior teachers. Research on Aging. http://dx.doi.org/10.1177/ $0164027513519449,0164027513519449$.

Zhang, L. F. (2007). Teaching styles and occupational stress among Chinese university faculty members. Educational Psychology, 27(6), 823-841. https://doi.org/10.1080/01443410701366043

\section{Copyright Disclaimer}

Copyright for this article is retained by the author(s), with first publication rights granted to the journal.

This is an open-access article distributed under the terms and conditions of the Creative Commons Attribution license (http://creativecommons.org/licenses/by/3.0/). 